\title{
Antarctic Krill Oil Attenuates Oxidative Stress via the KEAP1-NRF2 Signaling in Patients with Coronary Heart Disease
}

\author{
Chengfei Wen $\left(\mathbb{D},{ }^{1}\right.$ Mi Jiang, ${ }^{2}$ Weixin Huang, ${ }^{3}$ and Shumei Liu $\mathbb{D}^{4}$ \\ ${ }^{1}$ Department of Cardiology, The First Hospital of Jilin University, Changchun 130021, China \\ ${ }^{2}$ Department of Cardiac Surgery, The First Hospital of Jilin University, Changchun 130021, China \\ ${ }^{3}$ Department of Geriatrics, The First Hospital of Jilin University, Changchun 130021, China \\ ${ }^{4}$ Department of Endocrinology, The First Hospital of Jilin University, Changchun 130031, China \\ Correspondence should be addressed to Shumei Liu; liushumeijl@126.com
}

Received 23 December 2019; Revised 7 July 2020; Accepted 29 July 2020; Published 7 October 2020

Academic Editor: Shuang-En Chuang

Copyright (c) 2020 Chengfei Wen et al. This is an open access article distributed under the Creative Commons Attribution License, which permits unrestricted use, distribution, and reproduction in any medium, provided the original work is properly cited.

Background. Antarctic krill oil (AKO) has strong antioxidant activities and is effective for alleviating coronary heart disease (CHD). Kelch-like ECH-associated protein 1-NF-E2-related factor 2 (KEAP1-NRF2) axis is a crucial antioxidant signaling pathway. Thus, AKO may exert its antioxidant effects on CHD patients via KEAP1-NRF2 signaling. Methods. AKO fatty acid (FA) profiles were analyzed by using gas chromatography (GC). One hundred CHD patients were divided into the intervention (IG, AKO) and control (CG, placebo) groups. Before and after 1, 2, and 3 months of intervention, we measured serum levels of reactive oxygen species (ROS), 8-hydroxy-2-deoxyguanosine (8-OHdG), nitric oxide (NO), malondialdehyde (MDA), superoxide dismutase (SOD), reduced glutathione (GSH), and glutathione peroxidase (GPx), and KEAP1 and NRF2 levels in peripheral blood leukocytes (PBLs). Serum FAs were measured by GC at baseline and after 3-month intervention. Results. AKO contains rich eicosapentaenoic acid (EPA) and docosahexaenoic acid (DHA), which is more than $27 \%$ of total FA. The levels of EPA and DHA, KEAP1, and NRF2 in the IG group were higher than those in the CG group $(p<0.05)$. Serum levels of ROS, 8-OHdG, NO, and MDA in the IG group were lower than those in the CG group, whereas the levels of SOD, GSH, and GPx in the IG group were higher than those in the CG group $(p<0.05)$. Serum levels of saturated fatty acids (UFA) in the IG group were higher than those in the CG group, whereas reverse results were obtained for the levels of saturated fatty acids (SFA). Serum levels of EPA and DHA had a strong negative relationship with the level of ROS, whereas the ROS level had a strong negative relationship with the levels of KEAP1-NRF2. Conclusion. AKO increases antioxidant capacities of CHD patients via the KEAP1-NRF2 signaling in the PBL.

\section{Introduction}

Coronary heart disease (CHD) is the leading cause of global mortality [1]. Treating CHD is challenging mainly due to poor prognosis and clinical outcomes affected by systemic hypertension [2], atherosclerosis [3], and inflammatory factors [4]. Oxidative stress often induces hypertension [5], atherosclerosis [6], and inflammatory responses [7]. A high level of oxidative stress is closely associated with CHD progression [8], and antioxidant therapy has become a potential therapeutic option in the prevention of $\mathrm{CHD}$ risk $[9,10]$.
Previous work reported the protective role of krill oil intake against the risk of cardiovascular disease [11]. However, the clinical effects of AKO on $\mathrm{CHD}$ and related molecular mechanism remained widely unknown. EPA and DHA were reported to reduce the risks of heart disease for decades, and there has been increasing evidence that EPA and DHA consumption results in different clinical and molecular effects [12]. Antarctic krill oil (AKO) is rich with long-chain polyunsaturated fatty acids (LCPUFAs), such as eicosapentaenoic acid (EPA) and docosahexaenoic acid (DHA) [13], which may be especially important in antioxidant defenses. EPA showed strong antioxidant activity 
with obvious inhibitory function for alpha-diphenyl-betapicrylhydrazyl (DPPH) radical and 2, 20-azinobis-3-ethylbenzothiazoline-6-sulfonic acid (ABTS) radical cation [14]. DHA improved antioxidant status and reduced deoxyribonucleic acid damage [15]. A randomized and doubleblind parallel arm trial in overweight and obese patients showed that 4 weeks of AKO supplementation increased plasma contents of EPA and DHA without adverse effects on safety-related performance [16]. The results suggest that AKO may have protective functions for CHD patients by increasing antioxidant properties via EPA and DHA.

Kelch-like ECH-associated protein 1-NF-E2-related factor 2 (KEAP1-NRF2) is a widely reported antioxidant signaling pathway [17-20]. AKO may also exert its antioxidant activity by affecting KEAP1-NRF2 signaling via EPA and DHA. Thus, this study aimed to measure the EPA and DHA contents in AKO and explore the antioxidant effects of AKO dietary intervention on CHD patients by measuring the levels of oxidative stress-related parameters and KEAP1NRF2.

\section{Materials and Methods}

2.1. Measurement of Total Fatty Acid (FA) Composition in $A K O$. AKO was purchased from Hailisheng Group Co., Ltd. (Zhoushan, Zhejiang, China) and stored at $20^{\circ} \mathrm{C}$. The FA composition in $\mathrm{AKO}$ was analyzed using an Agilent 7820 gas chromatograph (Agilent; Wilmington, DE, USA) with the following method: 20 different patches of samples were tested in spiral test tubes, and $1 \mathrm{~mL}$ of a sodium hydroxidemethanol solution $(2 \mathrm{~mol} / \mathrm{L})$ was pipetted into each tube and methylated in a water bath at $80^{\circ} \mathrm{C}$ for $45 \mathrm{~min}$. After the reaction solution was cooled on ice, $2 \mathrm{~mL}$ of sulfuric acidmethanol solution $(0.5 \mathrm{~mol} / \mathrm{L})$ was added, and the methylated reaction was further performed in a water bath at $80^{\circ} \mathrm{C}$ for $45 \mathrm{~min}$; after taking it out again for cooling, $1 \mathrm{~mL}$ of chromatographic pure hexane was added for fatty acid methyl ester (FAME) extraction, and then saturated sodium chloride solution was added to promote the separation of the solution system. A small amount of anhydrous sodium sulfate was added to one half $\mathrm{mL}$ of centrifuge tube to dehydrate it. After passing through the membrane, the organic phase was transferred into a sample bottle for gas chromatography analysis. Gas chromatography conditions were set as follows: chromatographic column, trace TRFAME capillary column $(0.2 \mu \mathrm{m}, 60 \mathrm{~m} \times 0.25 \mathrm{~mm})$; inlet temperature, $230^{\circ} \mathrm{C}$; detector temperature, $250^{\circ} \mathrm{C}$; carrier gas flow rate, $1 \mathrm{~mL} / \mathrm{min}$; split ratio, $1: 100$. The programmed heating conditions were set as follows: the initial column temperature was maintained at $120^{\circ} \mathrm{C}$ for $2 \mathrm{~min}$; the temperature was increased at a rate of $5^{\circ} \mathrm{C} / \mathrm{min}$ to $175^{\circ} \mathrm{C}$, and the temperature was increased at a rate of $10^{\circ} \mathrm{C} / \mathrm{min}$ to $220^{\circ} \mathrm{C}$ and finally hold for $10 \mathrm{~min}$. 37-component FA methyl ester standard mixture (cat. CDAA-252795-MIX-1 mL) was purchased from ANPEL Scientific Instrument Co. Ltd. (Shanghai, China). Under the above chromatographic condition, a standard mixture of FAME was injected into the gas chromatograph, the chromatographic peaks were qualitatively determined, and the area normalization was used to determine the content of individual FA in the total FA mass (\%, wt). All FAMEs from AKO were normalized according to the FAME standards. The content of FA was calculated as $100 \%(\mathrm{w} / \mathrm{w})=$ content of each $\mathrm{FA} \times 100 /$ total relative FA contents for all FAs [21].

2.2. Participants. Before the experiments, all processes were approved by the Ethic Committee of The First Hospital of Jilin University (approval no. FHJLA20XY569) and consistent with the World Medical Association Declaration of Helsinki. From December 2017 to March 2018, 328 CHD patients visited our hospital and were recruited in our hospital. The written consent form was obtained from each subject.

2.2.1. Inclusion Criteria. CHD patients were proven by clinic, electrocardiogram, and selective coronary arteriography according to the diagnostic criteria for CHD [22, 23] and the standard questionnaire [24], and the patients aged more than 18 years.

2.2.2. Exclusion Criteria. The patients had mental diseases and were difficult to be communicated. The patients dropped out in time and would replenish the sample size in time. The patients had other serious diseases, such as cancers or liver diseases. Some patients took antioxidant drugs and healthy products with antioxidant activities.

2.2.3. Randomization. After inclusion and exclusion criteria, $100 \mathrm{CHD}$ patients were randomly assigned into the IG (received $2 \mathrm{~g}$ of AKO daily) and the CG (placebo) groups by using the random number generated by a computer, and the allocation ratio was $1: 1$. The dietary intervention periods were 3 months.

2.3. Measurement of Serum FA. All participants were fasted for $9 \mathrm{~h}$, and $5 \mathrm{~mL}$ of peripheral venous blood was collected into the BD Vacutainer tube. Blood samples were centrifuged at $5000 \times \mathrm{g}$ for $10 \mathrm{~min}$, and serum was obtained. Lipids were extracted along with triheptadecanoyl-glycerol, and FAMEs were made by using $6 \% \mathrm{H}_{2} \mathrm{SO}_{4}$ in methanol [25]. Individual FAs were separated and analyzed by using the above chromatographic condition. The contents of saturated fatty acids (SFA), monounsaturated fatty acids (MUFA), and polyunsaturated fatty acids (PUFA) were compared among the IG and CG groups.

2.4. Measurement of Serum Oxidative Parameters. Serum reactive oxygen species (ROS) was measured using N,Ndiethyl-para-phenylenediamine (DEPPD) (Sigma-Aldrich, USA) [26]. Serum 8-hydroxy-2-deoxyguanosine (8-OHdG) was measured using ELISA kit from the Japan Institute for the Control of Aging (Fukuroi, Shizuoka). Solution I ( $4.37 \mu \mathrm{M}$ of ferrous sulfate in $0.1 \mathrm{M}$ sodium acetate buffer, $\mathrm{pH} 4.8)$ and solution II $(100 \mu \mathrm{g} / \mathrm{ml}$ of DEPPD in $0.1 \mathrm{M}$ 
sodium acetate buffer, $\mathrm{pH}$ 4.8) were used to construct the calibration curve of ROS. Five $\mu \mathrm{l}$ of $\mathrm{H}_{2} \mathrm{O}_{2}$ was added to $140 \mu \mathrm{L}$ of $0.1 \mathrm{M}$ sodium acetate buffer ( $\mathrm{pH} 4.8$ ) in each well of a 96-well microtiter plate and incubated at $37^{\circ} \mathrm{C}$ after $5 \mathrm{~min}$. One hundred $\mu \mathrm{L}$ of solution I and $5 \mu \mathrm{L}$ of solution II were mixed, added to each cell and incubated at $37^{\circ} \mathrm{C}$ for $5 \mathrm{~min}$. The absorbing values were measured at $505 \mathrm{~nm}$ by using a spectrophotometric plate at $15 \mathrm{~s}$ intervals for $3 \mathrm{~min}$. A calibration curve was plotted according to the value variation (min) corresponding to the concentration of $\mathrm{H}_{2} \mathrm{O}_{2}$ (1 unit $=1.0 \mathrm{mg} \mathrm{H}_{2} \mathrm{O}_{2} / \mathrm{L}$ ). Five $\mu \mathrm{L}$ of serum was added to $140 \mu \mathrm{L}$ of $0.1 \mathrm{M}$ sodium acetate buffer ( $\mathrm{pH} 4.8$ ) in each well of a 96well microtiter plate and incubated at $37^{\circ} \mathrm{C}$ after $5 \mathrm{~min}$. One hundred $\mu \mathrm{L}$ of solution I and $5 \mu \mathrm{L}$ of solution II were mixed and added to the cuvette. The cuvette was incubated for $5 \mathrm{~min}$ at $37^{\circ} \mathrm{C}$. The absorbing values were measured at $505 \mathrm{~nm}$ for $3 \mathrm{~min}$. The ROS levels were calculated according to the calibration curve.

A series of 8-OHdG standards were diluted in the concentration ranging from $0 \mathrm{ng} / \mathrm{mL}$ to $20 \mathrm{ng} / \mathrm{mL}$ by using the assay diluent. The serum sample was diluted in assay diluent and filtered through a $0.45 \mu \mathrm{m}$ filter. Fifty $\mu \mathrm{L}$ of the sample or 8-OHdG standard was added to the wells of the 8OHdG conjugate coated plate and incubated for $10 \mathrm{~min}$ at room temperature on an orbital shaker. Fifty $\mu \mathrm{L}$ of the diluted anti-8-OHdG antibody was added to each well and incubated at room temperature for $1 \mathrm{~h}$ on an orbital shaker. The wells were washed with $250 \mu \mathrm{L}$ of washing buffer for 3 times. One hundred $\mu \mathrm{L}$ of the diluted secondary antibodyenzyme conjugate was added to each well and incubated at room temperature for 1 hour on an orbital shaker. The wells were washed for 3 times according the above method. One hundred $\mu \mathrm{L}$ of substrate solution was added to each well and incubated at room temperature on an orbital shaker for 20-30 min according the color changes. One hundred $\mu \mathrm{L}$ of stop solution was added to each well, and absorbing values were measured at $450 \mathrm{~nm}$. A standard curve was constructed by using the series of 8-OHdG standards, and the contents of 8-OHdG were calculated based on the standard curve.

Serum nitric oxide (NO) was determined using the Griess method (Invitrogen, CA, USA). Serum malondialdehyde (MDA) was measured using the thiobarbituric acid-trichloroacetic acid (TBA-TCA) method [27]. Serum superoxide dismutase (SOD) activity was analyzed by using a SOD kit (Nanjing Jiancheng Bioengineering Institute). Serum reduced glutathione (GSH) was determined using ELISA reagent kit from Shanghai BlueGene Biotech Co. (Shanghai, China). Serum glutathione peroxidase (GPx) activity was measured using the Cayman GPx Assay Kit (Cayman Chemical Company, Ann Arbor, MI, USA). Serum SOD was analyzed by examining the inhibition of hydroxylamine oxidation using a SOD-detection assay kit (Jiancheng Bioengineering, Nanjing, China) [28]. Hydroxylamine oxidation capacity was measured at 450 by using a spectrophotometer (Shimadzu, Japan). One unit of SOD was defined as the amount of enzyme that inhibited hydroxylamine oxidation by $50 \%$. Serum GSH was determined by using a kit from Shanghai BlueGene Biotech Co. (Shanghai, China) by using the spectrophotometric method [29]. The levels of yellow products were measured at $405 \mathrm{~nm}$ using a spectrophotometer (Shimadzu, Japan). Serum glutathione peroxidase (GPx) was measured by detecting the changes of $\mathrm{NADPH}$ to $\mathrm{NADP}^{+}$content using a Cayman GPx Assay Kit (Cayman Chemical Company, Ann Arbor, MI, USA) [30]. $\mathrm{NADPH}$ concentration was measured at $340 \mathrm{~nm}$ by using a spectrophotometer (Shimadzu, Japan). One unit of GPx was defined as $\mu \mathrm{m}$ of NADPH oxidized per min.

2.5. Quantitative Real-Time PCR (qRT-PCR) Analysis. Four $\mathrm{mL}$ of heparinized blood was obtained from each subject, and peripheral blood leukocytes (PBLs) were isolated by using density-gradient centrifugation over Histopaque-1077 (Sigma-Aldrich, USA). Total RNA was isolated by using the RNA extraction kit (Sanggon Biotech Co., Ltd. Shanghai, China). One $\mu$ g of RNA was reversely transcribed by using Transcriptor First Strand cDNA Synthesis Kit (Roche, Germany). The following primers were synthesized by TaKaRa (Dalian, China): KEAP1 (forward primer, $5^{\prime}$-catggcaaccgcaccttcag- $3^{\prime}$ and reverse primer, $5^{\prime}$-ctcagtggaggcgtacatca- $3^{\prime}$ ), NRF2 (forward primer, $5^{\prime}$-aacacacggtccacagctc- $3^{\prime}$ and reverse primer, $5^{\prime}$-tcttgcctccaaagtatgtcaa- $3^{\prime}$ ), and $\beta$-actin (forward primer, $5^{\prime}$-tcctccctggagaagagcta- $3^{\prime}$ and reverse primer, $5^{\prime}$-gcactgtgttggcatacagg- $3^{\prime}$ ) as an internal control. The qRT-PCR was performed as follows: 1 cycle of $94^{\circ} \mathrm{C}$ for $50 \mathrm{~s}$, followed by 40 cycles of $94^{\circ} \mathrm{C}$ for $15 \mathrm{~s}, 60^{\circ} \mathrm{C}$ for $15 \mathrm{~s}$, and $1 \mathrm{cycle}$ of $65^{\circ} \mathrm{C}$ for $50 \mathrm{~s}$. Relative mRNA levels of NRF2 and KEAP1 were normalized to the level of $\beta$-actin and analyzed using the $2^{-\Delta \Delta \mathrm{C}} \mathrm{T}$ method. Fold change in relative mRNA levels was analyzed based on the $2^{-\Delta \Delta \mathrm{Ct}}$ method, where $\Delta \Delta \mathrm{Ct}=2^{-\Delta \Delta \mathrm{Ct}}=[(\Delta \mathrm{Ct}$ target gen$\mathrm{e}-\Delta \mathrm{Ct}$ control) in the IG group $-[(\Delta \mathrm{Ct}$ target gene $-\Delta \mathrm{Ct}$ control) in the CG group].

2.6. Western Blot. PBLs were lysed with the buffer containing $50 \mathrm{mM}$ EDTA, $50 \mathrm{mM} \mathrm{NaCl}, 1 \% \mathrm{SDS}$, and $200 \mu \mathrm{g} / \mathrm{ml}$ proteinase $\mathrm{K}$ and treated at $37^{\circ} \mathrm{C}$ for $6 \mathrm{~h}$ [31]. The proteins were separated by $10 \%$ polyacrylamide gel and transferred to polyvinylidenedifluoride (PVDF) membranes (Millipore, CA, USA). The membrane was blocked with $5 \%$ nonfat milk and incubated with NRF2 (ab31163, 1:2000, Abcam), KEAP1 (ab139729, $1: 1000$, Abcam), and $\beta$-actin antibodies (ab8227, 1:5000, Abcam) from Abcam overnight at $4^{\circ} \mathrm{C}$. The membrane was then incubated with secondary antibody goat anti-rabbit IgG H\&L (HRP) (ab6721, 1:3000) for $2 \mathrm{~h}$ at room temperature. Immunoreactivity bands were visualized by using ECL Prime (GE Healthcare Science) and analyzed using a VersaDoc 5000 System (Bio-Rad). Quantification was estimated using ImageJ software (version 1.42; the National Institutes of Health, Bethesda, MD, USA).

2.7. Immunofluorescence Staining. The nuclear translocation of NRF2 and KEAP1 was detected via immunofluorescence staining. PBL cells $\left(1 \times 10^{4} / \mathrm{ml}\right)$ were cultured in laser confocal Petri dishes, treated with andrographolide sodium bisulfate (ASB) for $1 \mathrm{~d}$, and irradiated with UV $(300 \mu \mathrm{W} / \mathrm{cm} 2$ $\sec \times 300 \mathrm{sec})$. PBL were washed 4 times with PBS and fixed 
with $4 \%$ paraformaldehyde for $20 \mathrm{~min}$ at room temperature, permeabilized with $1 \%$ Triton $X$ for $20 \mathrm{~min}$, and then washed and blocked with 5\% goat serum (Invitrogen, Frederick, MD, USA) for half an hour. PBL were incubated with primary antibodies (NRF2, 1:2000, and KEAP1, 1:2000) at $4^{\circ} \mathrm{C}$ overnight, washed with TBST from G-Biosciences (St. Louis, MO, USA), and incubated with a secondary antibody conjugated to a fluorochrome (FITC, Enzo Life Sciences, $\mathrm{NY}$, USA) for $2 \mathrm{~h}$ at room temperature. PBL were stained with DAPI $(10 \mu \mathrm{g} / \mathrm{ml})$ for $10 \mathrm{~min}$, washed with PBST 3 times, and drawn on the slides with a drop of the fluorescent mounting medium. The antibody localization was visualized using a fluorescence microscope (EVOS; Life Technologies, USA).

2.8. Statistical Analysis. All data were analyzed using SPSS 22 statistical software (IBM SPSS, Armonk, NY, USA). Two groups of patients in the general social demographic data were expressed in the qualitative data using the f-test. The analysis of variance (ANOVA) was performed by using the Kruskal-Wallis rank sum test. The two-sided test was used to detect overall differences between the two groups, and the test level $a=0.05$. The analysis of one-way ANOVA was performed to test multiple comparisons between the two groups. Pearson's correlation coefficient test was used to explore the statistical relationship between serum levels of EPA or DHA and ROS level, and between ROS level and KEAP1, or NRF2 level in PBL.

\section{Results}

3.1. The FA Components of AKO. According to FAME standard (Figure 1(a)), krill oil boasts an impressive FA profile and contains two omega-3 PUFA, eicosapentaenoic acid (EPA) and docosahexaenoic acid (DHA), which were more than $27 \%$ of total FAs (Figure 1(b) and Table 1). As a plankton, the lipids in Antarctic krill mainly come from the food marine single-cell algae, such as diatoms with high levels of EPA and flagellates with high levels of DHA [32-35], which is why Antarctic krill oil contains high levels of EPA and DHA.

3.2. Demographic Data. In this study, $100 \mathrm{CHD}$ patients who met the selection criteria were included. In the IG group, there were 26 males and 24 females, aged 52-69 years, and average was $60.30 \pm 8.40$ years old. In the CG group, there were 24 males and 26 females, aged 47-71 years, and average was $58.56 \pm 12.23$ years. Demographic data included age, gender, smoking history, preoperative nutritional status, and BMI (the body mass index). There was no statistically significant difference during surgery (Table 2, $p>0.05$ ).

3.3. AKO Improved Antioxidant Properties in CHD Patients. Before AKO intervention, the statistical difference for ROS levels was insignificant between the two groups (Figure 2, $p>0.05)$. After AKO intervention, ROS level reduced in the IG group with the time going, whereas the level changed little in the CG group. ROS level in the IG group was lower than that in the CG group (Figure 2, $p<0.05$ ). The results suggest that $\mathrm{AKO}$ intervention reduces oxidative stress in the CHD patients.

In the similar cases, before $\mathrm{AKO}$ intervention, the statistical differences for the serum levels of 8 -OHdG (Figure 3(a))), NO (Figure 3(b)), and MDA (Figure 3(c)) were insignificant between the two groups $(p>0.05)$. After AKO intervention, the levels were reduced in the IG group with the time going, whereas the levels were changed little in the CG group. The levels of $8-\mathrm{OHdG}$ (Figure 3(a)), NO (Figure 3(b)), and MDA (Figure 3(c)) in the IG group were lower than those in the CG group $(p<0.05)$. The results also suggest that $\mathrm{AKO}$ intervention reduces oxidative stress in the CHD patients.

For the antioxidant biomarkers, the statistical differences for the serum levels of SOD (Figure 3(d)), GSH (Figure 3(e)), and GPx (Figure 3(f)) were insignificant between the two groups $(p>0.05)$. In contrast, after AKO intervention, the levels were increased in the IG group with the time going, whereas the levels changed little in the CG group. The serum levels of SOD (Figure 3(d)), GSH (Figure 3(e)), and GPx (Figure 3(f)) in the IG group were higher than those in the CG group $(p<0.05)$. The results also suggest that AKO intervention increases antioxidant capacities in the $\mathrm{CHD}$ patients.

3.4. AKO Improved Serum Levels of EPA and DHA in CHD Patients. Before AKO intervention, the statistical differences for the serum levels of EPA (Figure 4(a)) and DHA (Figure 4(b)) were insignificant between the two groups $(p>0.05)$. After AKO intervention, serum levels of EPA (Figure 4(a)) and DHA (Figure 4(b)) were significantly increased in the IG group, whereas the level changed little in the CG group. The serum levels of EPA and DHA in the IG group were significantly higher than that in the CG group $(p<0.05)$. The results suggest that AKO intervention increased the serum level of EPA and DHA in the CHD patients.

\subsection{AKO Increased Relative $m R N A$ Levels of KEAP1 and NRF2} in CHD Patients. Before AKO intervention, the statistical difference for relative mRNA levels of KEAP1 (Figure 5(a)) and NRF2 (Figure 5(b)) was insignificant between two groups $(p>0.05)$. After AKO intervention, relative mRNA levels of KEAP1 (Figure 5(a)) and NRF2 (Figure 5(b)) increased in the IG group and higher than those in the CG group $(p<0.05)$. The results suggest that AKO intervention may affect antioxidant capacities by increasing relative mRNA levels of KEAP1 and NRF2 levels in CHD patients.

3.6. AKO Increased Relative Protein Levels of KEAP1 and NRF2 in CHD Patients. Before AKO intervention, the statistical difference for relative protein levels of KEAP1 (Figure 6(a)) and NRF2 (Figure 6(b)) was insignificant between two groups $(p>0.05)$. After AKO intervention, relative protein levels of KEAP1 (Figure 6(a)) and NRF2 (Figure 6(b)) 


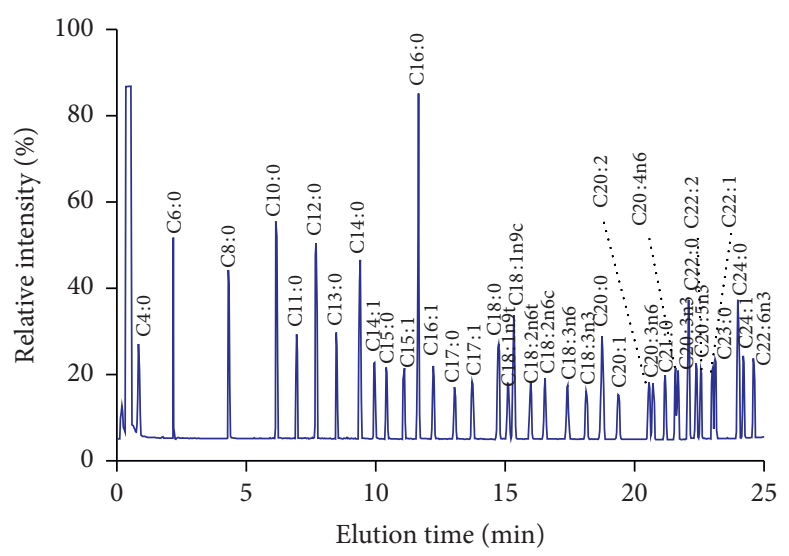

(a)

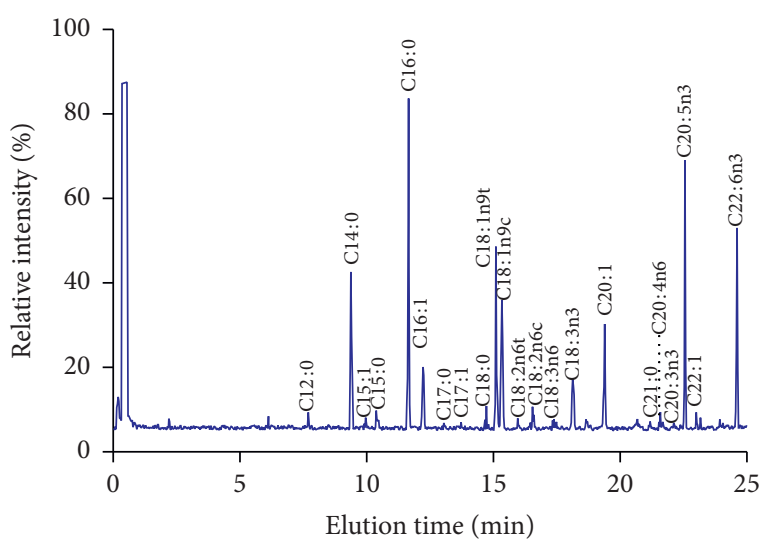

(b)

FIGURE 1: Gas chromatography analysis of fatty acid methyl esters: (a) fatty acid methyl ester standard mixture (37 components, C4-C24); (b) fatty acid methyl esters from AKO.

TABle 1: Fatty acid composition of Antarctic krill oil extracted with different solvents.

\begin{tabular}{|c|c|c|}
\hline Fatty acids & Content percent & Types \\
\hline $\mathrm{C} 12: 0$ & $0.22 \pm 0.05$ & SFA \\
\hline $\mathrm{C} 14: 0$ & $10.25 \pm 0.23$ & SFA \\
\hline $\mathrm{C} 14: 1$ & $0.21 \pm 001$ & MUFA \\
\hline $\mathrm{C} 15: 0$ & $0.45 \pm 0.03$ & SFA \\
\hline $\mathrm{C} 16: 0$ & $21.99 \pm 0.11$ & SFA \\
\hline $\mathrm{C} 16: 1$ & $4.79 \pm 0.05$ & MUFA \\
\hline $\mathrm{C} 17: 0$ & $0.14 \pm 0.02$ & SFA \\
\hline $\mathrm{C} 17: 1$ & $0.20 \pm 0.02$ & MUFA \\
\hline $\mathrm{C} 18: 0$ & $1.19 \pm 0.15$ & SFA \\
\hline $\mathrm{C} 18: \ln 9 \mathrm{t}$ & $10.83 \pm 0.17$ & MUFA \\
\hline $\mathrm{C} 18: \ln 9 \mathrm{c}$ & $7.67 \pm 0.12$ & MUFA \\
\hline $\mathrm{C} 18: 2 \mathrm{n} 6 \mathrm{t}$ & $0.30 \pm 0.01$ & PUFA \\
\hline $\mathrm{C} 18: 2 \mathrm{n} 6 \mathrm{c}$ & $2.01 \pm 0.11$ & PUFA \\
\hline $\mathrm{C} 18: 3 \mathrm{n} 6$ & $0.32 \pm 0.02$ & PUFA \\
\hline $\mathrm{C} 18: 3 \mathrm{n} 3$ & $2.30 \pm 0.03$ & PUFA \\
\hline $\mathrm{C} 20: 1$ & $6.27 \pm 0.12$ & MUFA \\
\hline $\mathrm{C} 21: 0$ & $0.18 \pm 0.02$ & SFA \\
\hline $\mathrm{C} 20: 4 \mathrm{n} 6$ & $0.37 \pm 0.01$ & PUFA \\
\hline $\mathrm{C} 20: 3 \mathrm{n} 3$ & $0.18 \pm 0.02$ & PUFA \\
\hline $\mathrm{C} 22: 1$ & $0.69 \pm 0.05$ & MUFA \\
\hline $\mathrm{C} 20: 5 \mathrm{n} 3$ & $17.40 \pm 0.17$ & PUFA \\
\hline $\mathrm{C} 22: 6 \mathrm{n} 3$ & $11.26 \pm 1.04$ & PUFA \\
\hline SFA & $34.42 \pm 0.08$ & - \\
\hline MUFA & $30.95 \pm 0.23$ & - \\
\hline PUFA & $34.63 \pm 0.21 b c$ & - \\
\hline PUFA $n-3$ & $31.63 \pm 0.19 b$ & - \\
\hline
\end{tabular}

Note: SFA, saturated fatty acid; MUFA, monounsaturated fatty acid; PUFA, polyunsaturated fatty acid.

increased in the IG group and higher than those in the CG group $(p<0.05)$. The results suggest that AKO intervention increases antioxidant capacities by increasing relative protein levels of KEAP1 and NRF2 levels in CHD patients.

Fluorescence staining also showed the similar results as Western blot analysis. The intensity of KEAP1 fluorescence were similar before and after 1, 2, and 3 months of intervention in the CG group (Figure $7(\mathrm{a})$ ). In contrast, the intensity of KEAP1 fluorescence increased and reached highest level after 3 months of AKO intervention in the IG group (Figure 7(b)). Similarly, the intensity of NRF2 fluorescence was similar before and after 1, 2, and 3 months of intervention in the CG group (Figure 7(c)). In contrast, the intensity of NRF2 fluorescence increased and reached highest level after 3 months of $\mathrm{AKO}$ intervention in the IG group (Figure $7(\mathrm{~d})$ ). The results also suggest that AKO intervention increases protein levels of KEAP1 and NRF2 levels in CHD patients. 
TABLE 2: Baseline characteristics between the two groups.

\begin{tabular}{|c|c|c|c|c|}
\hline Parameters & IG & CG & $\mathrm{t} / \chi^{2} / \mathrm{f}$-ratio & $p$ values \\
\hline $\begin{array}{l}\text { Age (age) } \\
\text { Male, } n(\%) \\
\text { Smoking, } n(\%) \\
\end{array}$ & $\begin{array}{l}60.30 \pm 8.40 \\
26(52.00) \\
25(50.00) \\
\end{array}$ & $\begin{array}{c}58.56 \pm 12.23 \\
24(48.00) \\
22(44.00) \\
\end{array}$ & $\begin{array}{l}0.625^{\mathrm{a}} \\
1.920^{\mathrm{b}} \\
0.361^{\mathrm{b}}\end{array}$ & $\begin{array}{l}0.525 \\
0.383 \\
0.548 \\
\end{array}$ \\
\hline $\begin{array}{l}\text { Education level, } n(\%) \\
\text { Junior high school and below } \\
\text { High school and above }\end{array}$ & $\begin{array}{l}30(60.00) \\
20(40.00)\end{array}$ & $\begin{array}{l}35(70.00) \\
15(30.00)\end{array}$ & $\begin{array}{c}1.099^{\mathrm{b}} \\
-\end{array}$ & $\begin{array}{c}0.295 \\
-\end{array}$ \\
\hline BMI $\left(\mathrm{kg} / \mathrm{m}^{2}\right)$ & $23.95 \pm 3.16$ & $23.64 \pm 4.06$ & $0.091^{\mathrm{a}}$ & 0.913 \\
\hline $\begin{array}{l}\text { CSA, cases (\%) } \\
\text { Grade 0 } \\
\text { Grade I } \\
\text { Grade II } \\
\text { Grade III } \\
\text { Grade IV } \\
\end{array}$ & $\begin{aligned} 4 & (8) \\
4 & (8) \\
28 & (56) \\
12 & (24) \\
& 2(4)\end{aligned}$ & $\begin{array}{c}3(6) \\
6(12) \\
25(50) \\
13(26) \\
3(6)\end{array}$ & $0^{c}$ & 1 \\
\hline $\begin{array}{l}\text { Drug history, cases (\%) } \\
\text { Antilipidemic } \\
\text { Hypoglycemic } \\
\text { Nitrates } \\
\text { Beta-blocker } \\
\text { Calcium antagonists } \\
\text { ACE-inhibitors } \\
\text { Diuretics }\end{array}$ & $\begin{aligned} 6 & (12) \\
2 & (4) \\
10 & (20) \\
24 & (48) \\
3 & (6) \\
4 & (8) \\
1 & (2)\end{aligned}$ & $\begin{array}{c}5(10) \\
3(6) \\
11(22) \\
22(44) \\
5(10) \\
3(6) \\
1(2)\end{array}$ & $0^{c}$ & 1 \\
\hline
\end{tabular}

Note: CAS, coronary artery spasm, refers to a sudden, intense vasoconstriction of an epicardial coronary artery which results in vessel occlusion or near occlusion. CAS was measured by $18 \mathrm{~F}$-fluorodeoxyglucose (18F-FDG). a stands for $t$ values, b stands for $\chi^{2}$ values, and c stands for f-ratio. $n=50$ in each group, and the statistical difference was insignificant if $p>0.05$.

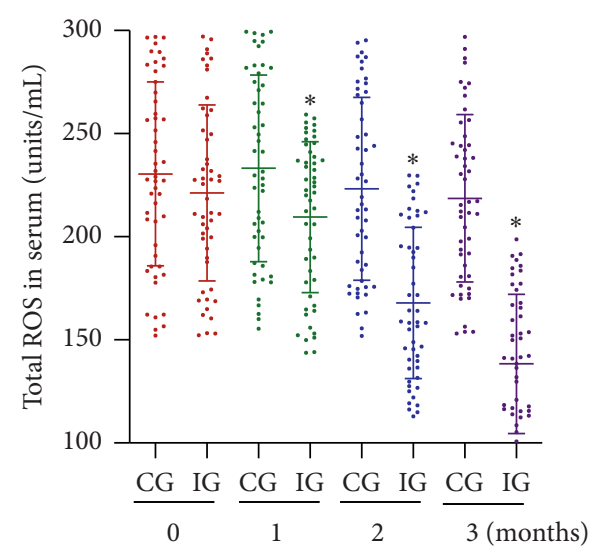

Figure 2: Serum level of reactive oxygen species (ROS). IG, Antarctic krill oil intervention group; CG, common-care group. $n=50$ for each group, and intervention duration was 3 months. The statistical difference was significant if $p<0.05$.

3.7. AKO Consumption Increased Serum UFA Contents and Reduced Serum SFA Contents. Before AKO intervention, the statistical difference for the serum contents of SFA, MUFA, PUFA, and PUFA-3 was insignificant between the two groups (Table 3, p>0.05). After 3 months of AKO intervention, the serum contents of SFA in the IG group were higher than those in the CG group, whereas the serum contents of MUFA, PUFA, and PUFA-3 had reverse results (Table 3, $p<0.05$ ). The results suggest that AKO intervention increases serum UFA contents and reduces serum SFA contents in $\mathrm{CHD}$ patients.

3.8. ROS Levels Had a Negative Relationship with Serum Levels ofEPA or DHA. The test of Spearman rank-order correlation coefficient showed that with the increase in serum SOD, the levels of serum EPA reduced (Figure 8(a), $p<0.001$ ). Similarly, the levels of serum DHA reduced (Figure $8(\mathrm{~b})$, $p<0.001)$ with the increase in the total SOD in serum. ROS levels had a negative relationship with serum levels of EPA 


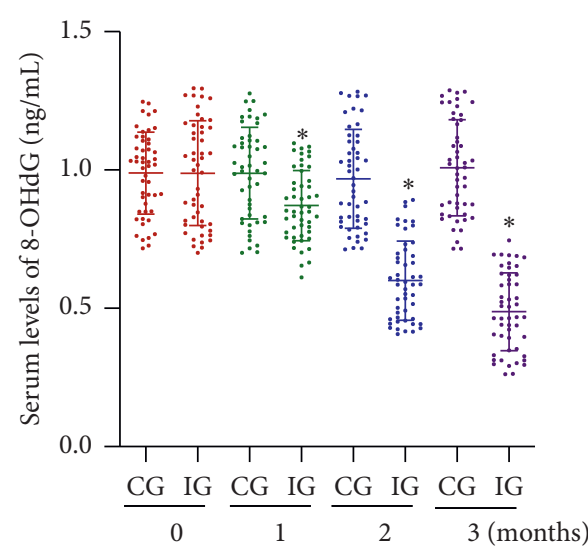

(a)

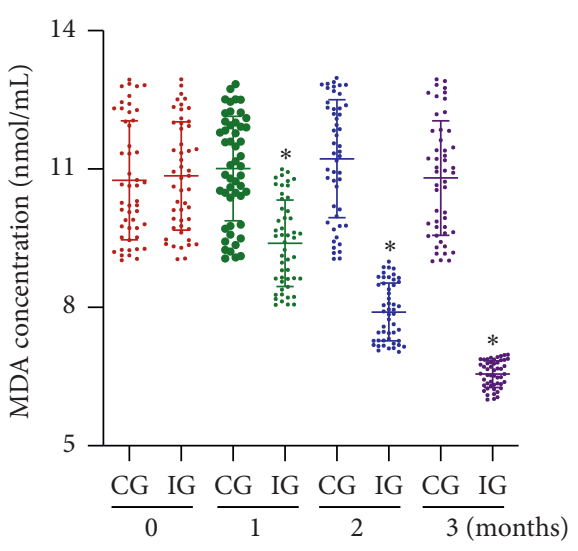

(c)

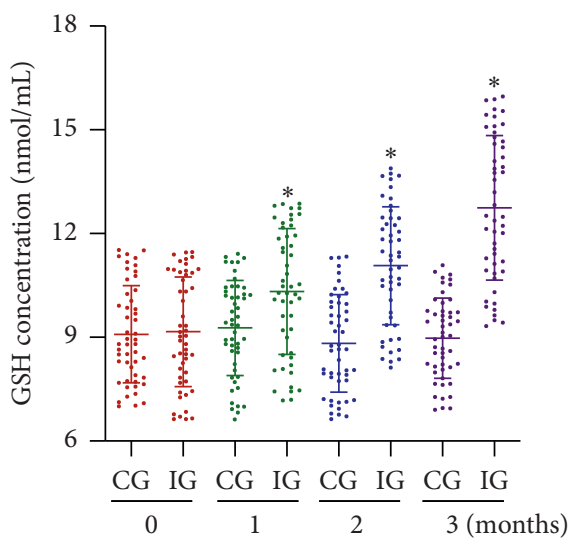

(e)

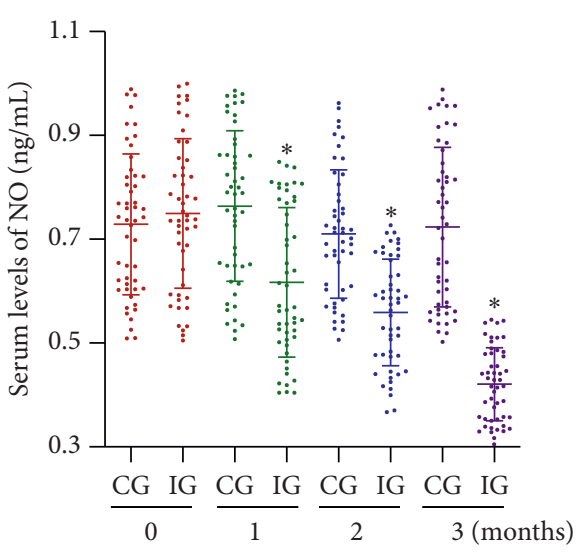

(b)

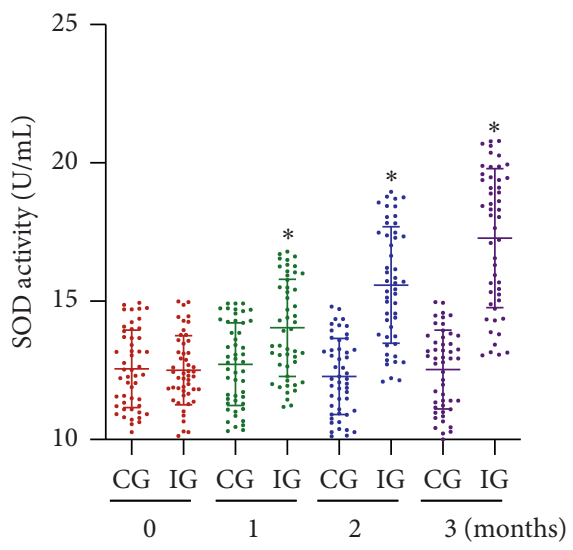

(d)

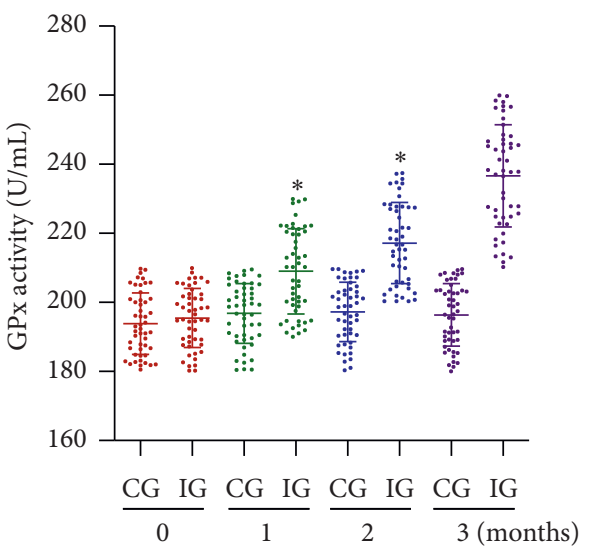

(f)

Figure 3: Serum levels of oxidative stress biomarkers: (a) 8-OHdG, 8-hydroxy-2-deoxyguanosine; (b) NO, nitric oxide; (c) MDA, malondialdehyde; (d) SOD, superoxide dismutase; (e) GSH, reduced glutathione; (f) GPx, glutathione peroxidase. IG, Antarctic krill oil intervention group; $C G$, common-care group. $n=50$ for each group, and intervention duration was 3 months. The statistical difference was significant if $p<0.05$.

or DHA, suggesting that EPA and DHA may reduce the total ROS in serum and have antioxidant capacities.

3.9. ROS Levels Had a Negative Relation with Relative Protein Levels of KEAP1 or NRF2. The test of Spearman rank-order correlation coefficient showed that with the increase in serum SOD, relative protein levels of KEAP1 reduced (Figure 9(a), $p<0.001$ ). Similarly, the levels of NRF2 also reduced (Figure $9(\mathrm{~b}), p<0.001$ ) with the increase in serum SOD. ROS levels had a negative relation with relative protein levels of KEAP1 and NRF2, suggesting that EPA and DHA may reduce serum ROS by affecting KEAP1 and NRF2 signaling. 


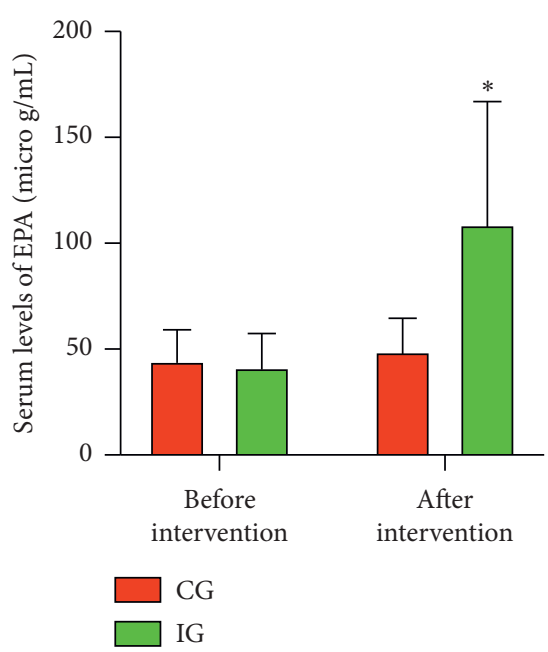

(a)

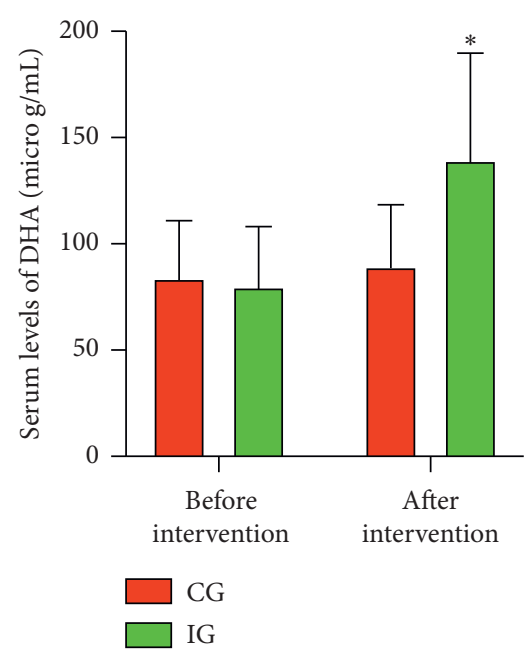

(b)

FIgURE 4: Serum levels of EPA and DHA in the CHD patients: (a) EPA; (b) DHA. IG, Antarctic krill oil intervention group; CG, commoncare group. $n=10$ in each group, and intervention duration was 3 months. The statistical difference was significant if $p<0.05$.

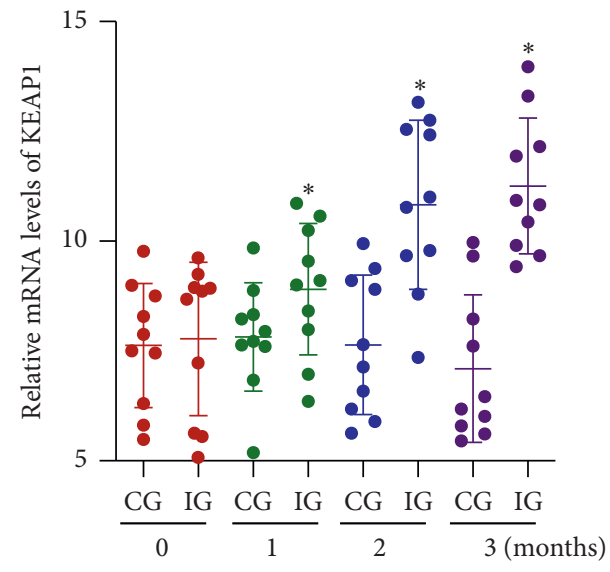

(a)

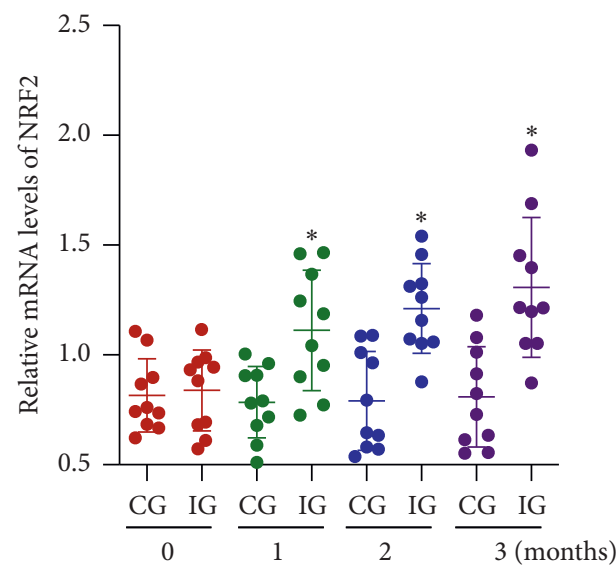

(b)

FIGURE 5: Relative mRNA levels of KEAP1 and NRF2 in the peripheral blood leukocytes (PBLs) of the patients with CHD: (a) KEAP1, Kelchlike ECH-associated protein; (b) NRF2, 1-NF-E2-related factor 2. IG, Antarctic krill oil intervention group; CG, a common-care group. $n=10$ in each group, and intervention duration was 3 months. The statistical difference was significant if $p<0.05$.

\section{Discussion}

The present work showed that AKO contains high levels of EPA and DHA (Table 1). AKO consumption improved lipid contents by reducing serum contents of SFA and increasing serum contents of MUFA and PUFA (Table 3). AKO intervention increased antioxidant capacity in the CHD patients by reducing the serum levels of oxidative biomarkers ROS (Figure 2), 8-OHdG, NO, and MDA (Figure 3), and increasing the levels of antioxidant biomarkers SOD, GSH, and GPx (Figure 3). Meanwhile, AKO treatment also activated antioxidant signaling KEAP1 and NRF2 in PBL (Figures 5-7). Serum levels of EPA and DHA had a strong negative relationship with the level of ROS (Figure 8), whereas ROS had a strong negative relation with the levels of KEAP1-NRF2 (Figure 9). Thus, all these findings imply that
AKO may improve antioxidant capacities in CHD patients by activating KEAP1 and NRF2 signaling via EPA and DHA.

$\mathrm{AKO}$ addition in the diet reduced serum contents of SFA and increased serum contents of MUFA and PUFA in CHD patients. The changes may be caused by the high levels of UFA and lower levels of SFA in AKO. AKO increased the antioxidant capacities in the CHD patients via EPA and DHA, which were consistent with that EPA and DHA had high levels of antioxidant activities [36, 37]. EPA has been found to show the greatest antioxidant activity by reducing $70 \%$ MDA level, followed by DHA, 2 of which have higher antioxidant activities than other omega-3 FA [38]. EPA and DHA should play important roles in the antioxidant activity of AKO.

KEAP1 and NRF2 are associated with antioxidant function [39], and activation of KEAP1/NRF2 signaling 


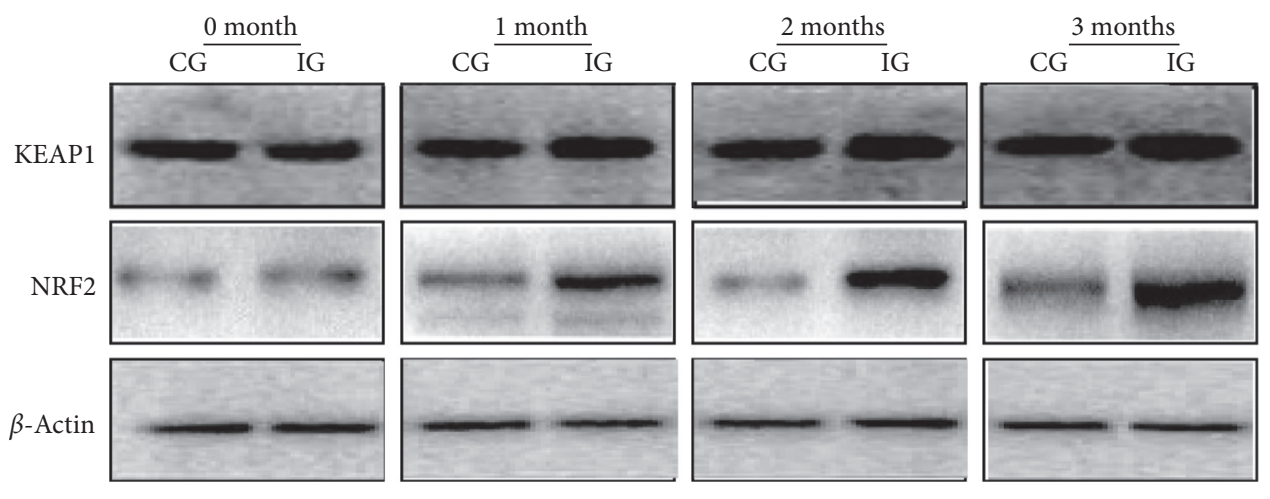

(a)

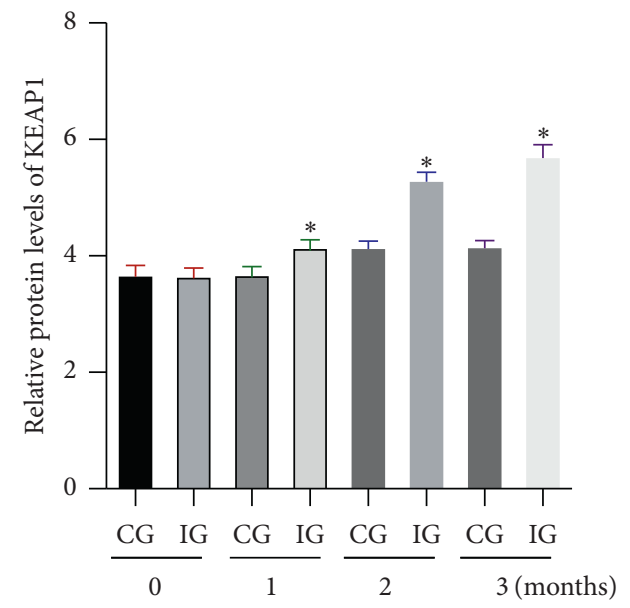

(b)

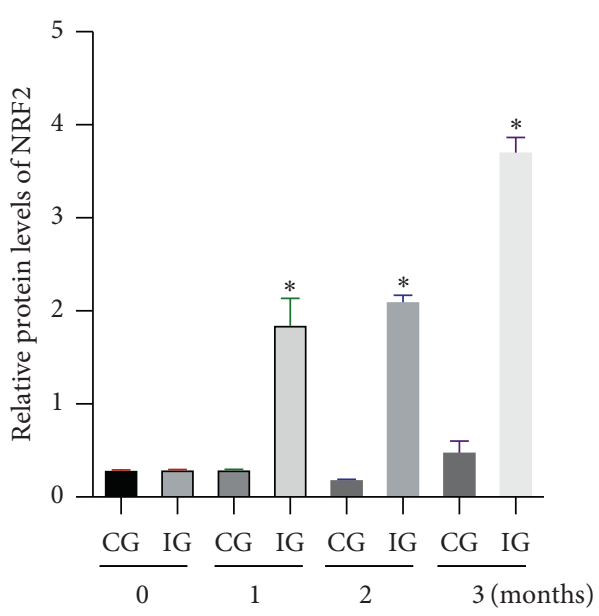

(c)

FIGURE 6: Relative protein levels of KEAP1 and NRF2 in the peripheral blood leukocytes (PBLs) of the patients with CHD: (a) KEAP1, Kelch-like ECH-associated protein; (b) NRF2, 1-NF-E2-related factor 2. IG, Antarctic krill oil intervention group; CG, a common-care group. $n=10$ in each group, and intervention duration was 3 months. The statistical difference was significant if $p<0.05$.

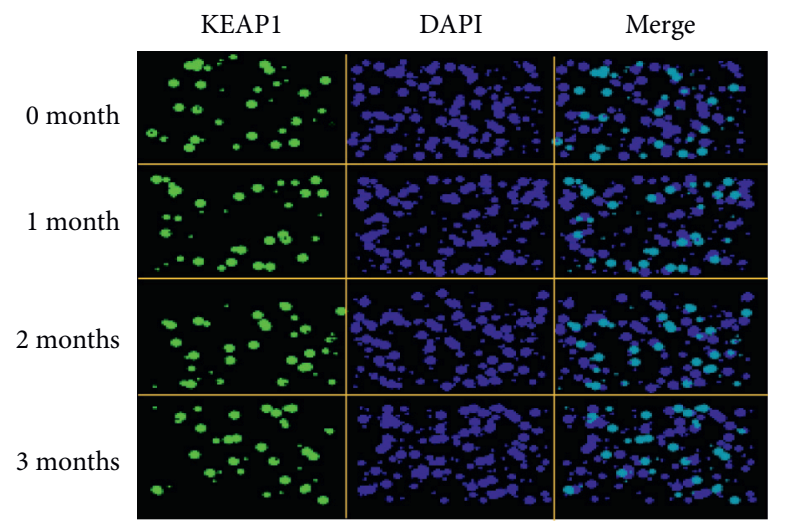

(a)

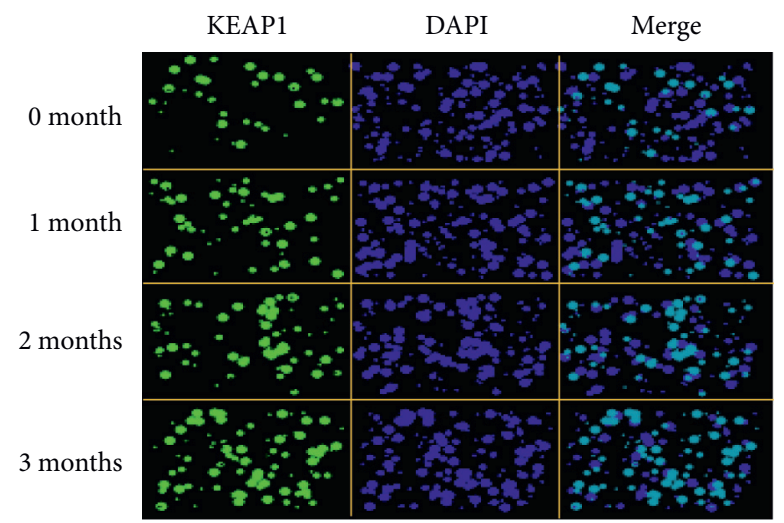

(b)

Figure 7: Continued. 


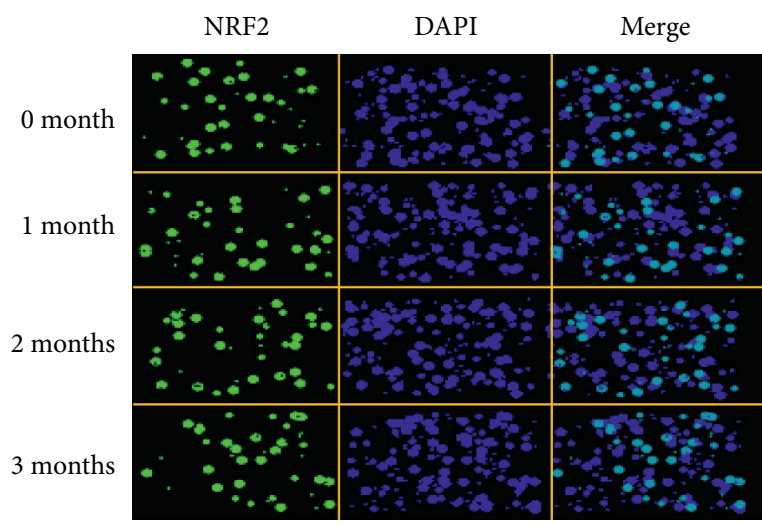

(c)

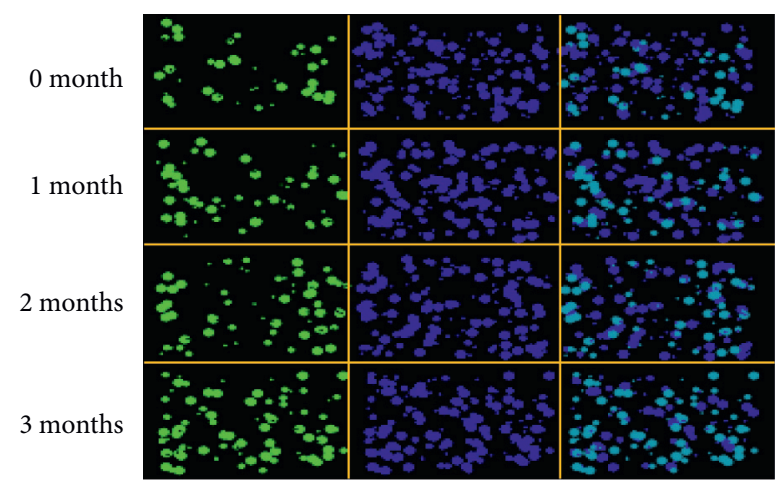

(d)

FIGURE 7: Immunofluorescence staining of peripheral blood leukocytes (PBLs): (a) the expression of KEAP1; (b) the expression of NRF2. The fluorescence localization of KEAP1 and NRF2 was measured with immunofluorescence. Anti-NRF2 and KEAP1 antibodies were used to detect NRF2 and KEAP1 localization (green) using a fluorescence microscope. DAPI staining indicated the locations of the nuclei (blue). $n=10$ in each group, and intervention duration was 3 months. (a) KEAP1 expression in the CG group. (b) KEAP1 expression in the IG group. (c) NRF2 expression in the CG group. (d) NRF2 expression in the IG group.

TABLE 3: The comparison of fatty acids between the IG and CG groups.

\begin{tabular}{lccc}
\hline Fatty acids (\% of total fatty acids) & IG & CG & $p$ values \\
\hline Before intervention & & & \\
SFA & $33.2(30.2,35.6)$ & $2.7(29.4,35.1)$ & 0.651 \\
MUFA & $24.5(20.3,26.7)$ & $25.3(21.4,27.8)$ & 0.529 \\
PUFA & $42.9(37.1,48.5)$ & $42.0(37.8,49.0)$ & 0.714 \\
PUFA $n-3$ & $7.8(5.3,9.6)$ & $8.2(5.6,10.4)$ & \\
After intervention & & & \\
SFA & $29.3(27.4,33.1)$ & $25.6(30.2,36.7)$ & 0.006 \\
MUFA & $27.1(22.5,29.2)$ & $39.4(36.1,48.5)$ & 0.015 \\
PUFA & $43.6(38.3,49.7)$ & $7.2(5.2,9.6)$ & 0.038 \\
PUFA $n-3$ & $8.1(5.5,9.8)$ & 0.032 \\
\hline
\end{tabular}

Note: the median in the brackets was given from $25^{\text {th }}$ to $75^{\text {th }}$ percentile. MUFA, monounsaturated fatty acid; PUFA, polyunsaturated fatty acid; SFA, saturated fatty acid.

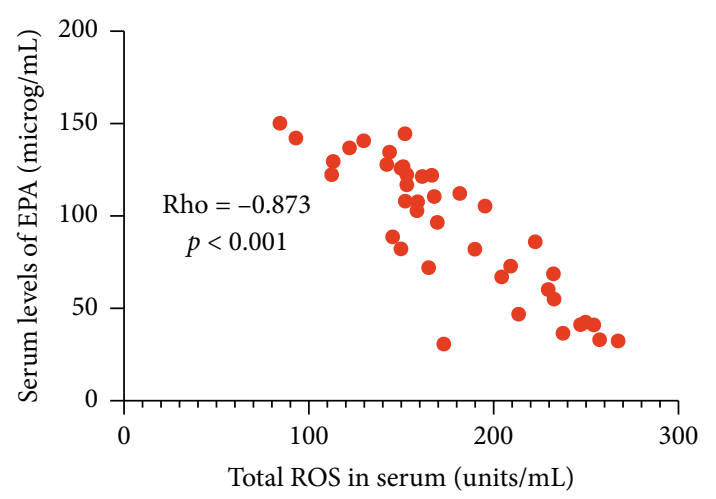

(a)

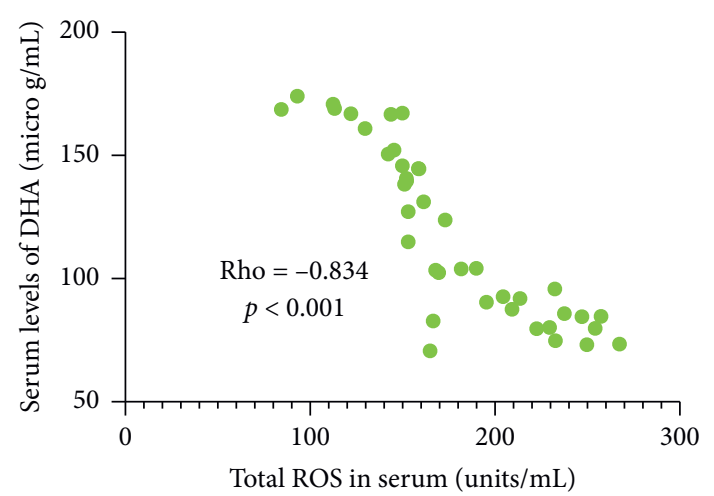

(b)

FIGURE 8: The test of Spearman rank-order correlation coefficient for the relation between the levels of ROS and serum levels of EPA or DHA: (a) EPA; (b) DHA. Rho $<-0.5$ means a strong negative correlation between two variables. 


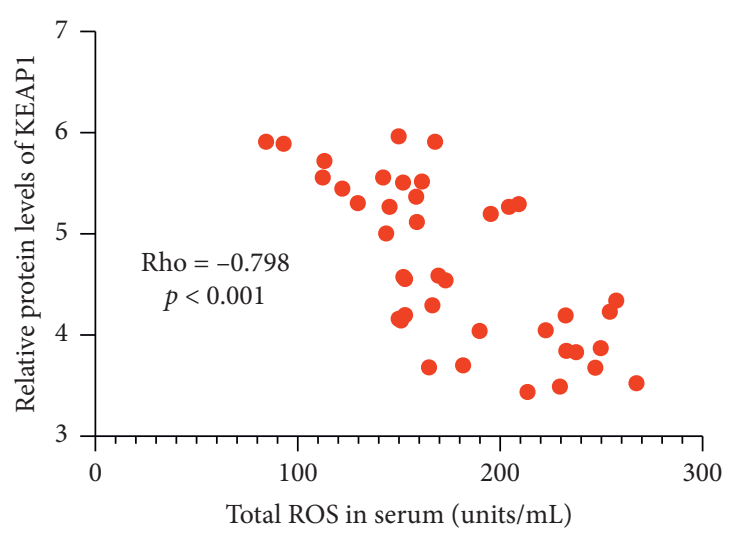

(a)

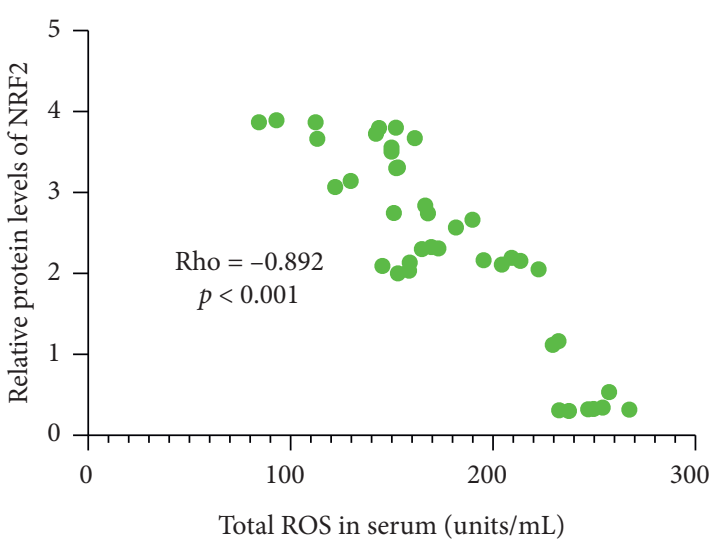

(b)

FIGURE 9: The test of Spearman rank-order correlation coefficient for the relation between the levels of ROS and relative protein levels of KEAP1 and NRF2: (a) KEAP1; (b) NRF2. Rho $<-0.5$ means a strong negative correlation between the two variables.

results in the increase of antioxidant activities [40]. However, the effects of EPA and DHA on KEAP1/NRF2 signaling remain widely unknown. The correction test indicated that ROS levels had negative relation with serum levels of EPA and DHA (Figure 8), and the levels of KEAP1 and NRF2 (Figure 9) in the CHD patients. Thus, EAP and DHA levels may have a strong relationship with the KEAP1 and NRF2 levels. Further work is needed to be done to confirm the conclusion.

\section{Limitations of This Study}

This study was a small sample and single-center study, and the research results may have a certain degree of bias. In order to control the bias, all the subjects in this study were from the same place and recruited in the same department of our hospital. The indicators after the patient were not studied for more than 3 months, so the long-term effect remains unclear. Total antioxidant capacity (TAC) and catalase are important other biomarkers [41] and were not studied in the present work. EPA and DHA have been found to have strong antiinflammatory effects [42], but the serum levels of inflammatory factors were not measured either. Much work is highly demanded to address these important issues.

\section{Data Availability}

The datasets generated and analyzed in this study are not publicly available because patient information is contained in the data, but all data are available from the correspondent author on reasonable request.

\section{Conflicts of Interest}

The authors declare that they have no conflicts of interest.

\section{References}

[1] G. Santulli, "Epidemiology of cardiovascular disease in the 21st century: updated numbers and updated facts," Journal of Cardiovascular Disease Research, vol. 1, no. 1, pp. 1-2, 2013.
[2] C. Wang, W. Yan, H. Wang, J. Zhu, and H. Chen, "APOE polymorphism is associated with blood lipid and serum uric acid metabolism in hypertension or coronary heart disease in a Chinese population," Pharmacogenomics, vol. 20, no. 14, pp. 1021-1031, 2019.

[3] Z. Wang, C. Zhu, V. Nambi et al., "Metabolomic pattern predicts incident coronary heart disease findings from the atherosclerosis risk in communities study," Arteriosclerosis, Thrombosis, and Vascular Biology, vol. 39, no. 7, pp. 14751482, 2019.

[4] A. Peikert, K. Kaier, J. Merz et al., "Residual inflammatory risk in coronary heart disease: incidence of elevated high-sensitive CRP in a real-world cohort," Clinical Research in Cardiology, vol. 109, pp. 315-323, 2019.

[5] K. A. Ahmad, D. Yuan Yuan, W. Nawaz et al., "Antioxidant therapy for management of oxidative stress induced hypertension," Free Radical Research, vol. 51, no. 4, pp. 428-438, 2017.

[6] R. Gopoju, S. Panangipalli, and S. Kotamraju, "Metformin treatment prevents SREBP2-mediated cholesterol uptake and improves lipid homeostasis during oxidative stress-induced atherosclerosis," Free Radical Biology \& Medicine, vol. 118, pp. 85-97, 2018.

[7] A. A. Ozturk and H. T. Kiyan, "Treatment of oxidative stress-induced pain and inflammation with dexketoprofen trometamol loaded different molecular weight chitosan nanoparticles: formulation, characterization and anti-inflammatory activity by using in vivo HET-CAM assay," Microvascular Research, vol. 128, Article ID 103961, 2020.

[8] N. Katakami, H. Kaneto, T. Matsuoka et al., "Accumulation of oxidative stress-related gene polymorphisms and the risk of coronary heart disease events in patients with type 2 diabetes an 8-year prospective study," Atherosclerosis, vol. 235, no. 2, pp. 408-414, 2014.

[9] F. Raygan, V. Ostadmohammadi, F. Bahmani, R. J. Reiter, and Z. Asemi, "Melatonin administration lowers biomarkers of oxidative stress and cardio-metabolic risk in type 2 diabetic patients with coronary heart disease: a randomized, doubleblind, placebo-controlled trial," Clinical Nutrition, vol. 38, no. 1, pp. 191-196, 2019.

[10] X. Y. Yang, T. M. He, S. J. Han et al., "The role of traditional chinese medicine in the regulation of oxidative stress in treating coronary heart disease. oxidative medicine and 
cellular longevity," Redox Control of Vascular Biology, vol. 2019, Article ID 3231424, 13 pages, 2019.

[11] A. Köhler, E. Sarkkinen, N. Tapola, T. Niskanen, and I. Bruheim, "Bioavailability of fatty acids from krill oil, krill meal and fish oil in healthy subjects-a randomized, singledose, cross-over trial," Lipids in Health and Disease, vol. 14, no. 1, p. 19, 2015.

[12] R. J. Deckelbaum and P. C. Calder, "Is it time to separate EPA from DHA when using omega-3 fatty acids to protect heart and brain?," Current Opinion in Clinical Nutrition \& Metabolic Care, vol. 23, no. 2, pp. 65-67, 2020.

[13] I. S. M. van der Wurff, C. von Schacky, T. Bergeland et al., "Exploring the association between whole blood omega-3 index, DHA, EPA, DHA, AA and n-6 DPA, and depression and self-esteem in adolescents of lower general secondary education," European Journal of Nutrition, vol. 58, no. 4, pp. 1429-1439, 2019.

[14] D. Lopes, T. Melo, J. Meneses et al., “A new look for the red macroalga palmaria palmata: a seafood with polar lipids rich in EPA and with antioxidant properties," Marine Drugs, vol. 17, no. 9, 553 pages, 2019.

[15] J. C. Martinez-Soto, J. C. Domingo, B. Cordobilla et al., "Dietary supplementation with docosahexaenoic acid (DHA) improves seminal antioxidant status and decreases sperm DNA fragmentation," Systems Biology in Reproductive Medicine, vol. 62, no. 6, pp. 387-395, 2016.

[16] K. C. Maki, M. S. Reeves, M. Farmer et al., "Krill oil supplementation increases plasma concentrations of eicosapentaenoic and docosahexaenoic acids in overweight and obese men and women," Nutrition Research, vol. 29, no. 9, pp. 609-615, 2009.

[17] E. Nadal, R. Palmero, and C. Munoz-Pinedo, "Mutations in the antioxidant KEAP1/NRF2 pathway define an aggressive subset of NSCLC resistant to conventional treatments," Journal of Thoracic Oncology, vol. 14, no. 11, pp. 1881-1883, 2019.

[18] A. Paunkov, D. V. Chartoumpekis, P. G. Ziros, and G. P. Sykiotis, "A bibliometric review of the keap1/nrf2 pathway and its related antioxidant compounds," Antioxidants (Basel), vol. 8, no. 9, 353 pages, 2019.

[19] A. Matana, P. G. Ziros, D. V. Chartoumpekis et al., "Rare and common genetic variations in the Keap1/Nrf2 antioxidant response pathway impact thyroglobulin gene expression and circulating levels, respectively," Biochemical Pharmacology, vol. 173, 2019.

[20] C. H. Zhou, F. Xue, S. S. Xue et al., "Electroacupuncture pretreatment ameliorates PTSD-like behaviors in rats by enhancing hippocampal neurogenesis via the keap1/nrf2 antioxidant signaling pathway," Frontiers Cellular Neuroscience, vol. 13, p. 275, 2019.

[21] K. E. Kaylegian, D. Dwyer, J. Lynch, D. Bauman, J. Fleming, and D. Barbano, "Impact of fatty acid composition on the accuracy of mid-infrared fat analysis of farm milks," Journal of Dairy Science, vol. 92, no. 6, pp. 2502-2513, 2009.

[22] G. T. W. Mander, K. Dobeli, C. Steffensen, and Z. Munn, "Diagnostic accuracy of computed tomography coronary angiography utilizing recent advances in technology in patients with high heart rates: a systematic review protocol," $J B I$ Database of Systematic Reviews and Implementation Reports, vol. 17, no. 7, pp. 1312-1318, 2019.

[23] C. J. White, M. R. Jaff, Z. J. Haskal et al., “American heart association committee on $\mathrm{d}$ et al: indications for renal arteriography at the time of coronary arteriography: a science advisory from the american heart association committee on diagnostic and interventional cardiac catheterization, council on clinical cardiology, and the councils on cardiovascular radiology and intervention and on kidney in cardiovascular disease," Circulation, vol. 114, no. 17, pp. 1892-1895, 2006.

[24] N. Oldridge, C. Cho, R. Thomas, M. Low, and S. Hofer, "Validation of the english version of the heartQoL healthrelated quality of life questionnaire in patients with coronary heart disease," Journal of Cardiopulmonary Rehabilitation and Prevention, vol. 38, no. 2, pp. 92-99, 2018.

[25] E. A. Szymlek-Gay, A. R. Gray, A.-L. M. Heath, E. L. Ferguson, and C. M. Skeaff, "Red meat consumption and serum lipids and fatty acids in toddlers: secondary outcomes of a randomized controlled trial," Journal of Pediatric Gastroenterology and Nutrition, vol. 67, no. 3, pp. 395-400, 2018.

[26] I. Hayashi, Y. Morishita, K. Imai, M. Nakamura, K. Nakachi, and T. Hayashi, "High-throughput spectrophotometric assay of reactive oxygen species in serum," Mutation Research/ Genetic Toxicology and Environmental Mutagenesis, vol. 631, no. 1, pp. 55-61, 2007.

[27] S. Paulose, V. Rangdhol, R. Ramesh, S. A. Jeelani, and S. Brooklyin, "Estimation of serum malondialdehyde and assessment of DNA damage using comet assay in patients with oral submucous fibrosis," Journal of Investigative and Clinical Dentistry, vol. 7, no. 3, pp. 286-293, 2016.

[28] J. Zhu, C. G. Wang, and Y. G. Xu, "Lycopene attenuates endothelial dysfunction in streptozotocin-induced diabetic rats by reducing oxidative stress," Pharmaceutical Biology, vol. 49, no. 11, pp. 1144-1149, 2011.

[29] M. Pandurangan, M. Veerappan, and D. H. Kim, "Cytotoxicity of zinc oxide nanoparticles on antioxidant enzyme activities and mRNA expression in the cocultured C2C12 and 3T3-L1 cells," Applied Biochemistry and Biotechnology, vol. 175, no. 3, pp. 1270-1280, 2015.

[30] H. An, X. Du, X. Huang et al., "Obesity, altered oxidative stress, and clinical correlates in chronic schizophrenia patients," Translational Psychiatry, vol. 8, no. 1, p. 258, 2018.

[31] T. Yabuta, K. Shinmura, M. Tani et al., "E-cadherin gene variants in gastric cancer families whose probands are diagnosed with diffuse gastric cancer," International Journal of Cancer, vol. 101, no. 5, pp. 434-441, 2002.

[32] E. Peltomaa, H. Hallfors, and S. J. Taipale, "Comparison of diatoms and dinoflagellates from different habitats as sources of PUFAs," Marine Drugs, vol. 17, no. 4, 2019.

[33] A. Jacobsen, O. Grahl-Nielsen, and T. Magnesen, "Effects of reduced diameter of bag cultures on content of essential fatty acids and cell density in a continuous algal production system," Journal of Applied Phycology, vol. 24, no. 1, pp. 109-116, 2012.

[34] K. Schmidt, C. Schlosser, A. Atkinson et al., "Zooplankton gut passage mobilizes lithogenic iron for ocean productivity," Current Biology, vol. 26, no. 19, pp. 2667-2673, 2016.

[35] C. F. Phleger, M. M. Nelson, B. D. Mooney, and P. D. Nichols, "Interannual and between species comparison of the lipids, fatty acids and sterols of antarctic krill from the US AMLR elephant island survey area," Comparative Biochemistry and Physiology B Biochemical and Molecular Biology, vol. 131, no. 4, pp. 733-747, 2002.

[36] S. F. Long, S. Kang, Q. Q. Wang et al., "Dietary supplementation with DHA-rich microalgae improves performance, serum composition, carcass trait, antioxidant status, and fatty acid profile of broilers," Poultry Science, vol. 97, no. 6, pp. 1881-1890, 2018.

[37] T. Leger, K. Azarnoush, A. Traore et al., "Antioxidant and cardioprotective effects of EPA on early low-severity sepsis 
through UCP3 and SIRT3 upholding of the mitochondrial redox potential," Oxidative Medicine and Cellular Longevity, vol. 2019, Article ID 9710352, 21 pages, 2019.

[38] S. C. Sherratt, R. A. Juliano, and R. P. Mason, "Eicosapentaenoic acid (EPA) has optimal chain length and degree of unsaturation to inhibit oxidation of small dense LDL and membrane cholesterol domains as compared to related fatty acids in vitro," Biochimica et Biophysica Acta (BBA)-Biomembranes, vol. 1862, no. 7, Article ID 183254, 2020.

[39] K. K. Nordgren and K. B. Wallace, "Disruption of the keap1/ nrf2-antioxidant response system After chronic doxorubicin exposure In vivo," Cardiovascular Toxicology, 2020.

[40] F. Tonolo, A. Folda, L. Cesaro et al., "Milk-derived bioactive peptides exhibit antioxidant activity through the Keap1-Nrf2 signaling pathway," Journal of Functional Foods, vol. 64, Article ID 103696, 2020.

[41] S. Fathi, S. Borzouei, M. T. Goodarzi, J. Poorolajal, and F. Ahmadi-Motamayel, "Evaluation of salivary antioxidants and oxidative stress markers in type 2 diabetes mellitus: a retrospective cohort study. endocrine, metabolic \& immune disorders-drug targets (formerly current drug targets-immune," Endocrine \& Metabolic Disorders), vol. 20, no. 4, pp. 584-590, 2020.

[42] E. J. Baker, C. A. Valenzuela, C. O. De Souza, P. Yaqoob, E. A. Miles, and P. C. Calder, "Comparative anti-inflammatory effects of plant-and marine-derived omega-3 fatty acids explored in an endothelial cell line," Biochimica et Biophysica Acta (BBA)-Molecular and Cell Biology of Lipids, vol. 1865, no. 6, Article ID 158662, 2020. 